\title{
La fuerza obligatoria del precedente de la Contraloría General de la República. Una regla chilena de stare decisis
}

\section{The binding force of the precedent laid down by the Comptroller General of the Republic. A Chilean rule of stare decisis}

Jaime Phillips Letelier

\begin{abstract}
Este artículo discute la regla de obligatoriedad del precedente de la Contraloría General de la República contenida en los artículos 6 y 19 de la Ley $N^{\circ}$ 10.336. No es usual que en sistemas de derecho continental se contemple este tipo de reglas. Se constata que los precedentes de este organismo, en ocasiones, no reciben una adecuada publicidad y son aplicados en casos futuros como si fuesen leyes generales y abstractas cuando, en realidad, se trata de pronunciamientos referidos a casos particulares,
\end{abstract}

This article discusses the binding precedent rule contained in articles 6 and 19 of Law No 10.366 which regulates the powers and functions of the General Comptroller's Office (CGR). This kind of rule is seldom found in Civil Law systems. Hence, its application can generate some shortcomings. In fact, it can be seen that the CGR's precedents, in some cases, are not properly published and that they are applied to future cases as if they were abstract rules, rather than decisions referred to particular cases which are

\footnotetext{
* Doctor en Derecho. Profesor de Derecho Administrativo, Universidad Finis Terrae. Dirección postal: Avenida Pedro de Valdivia 1509, Providencia, Santiago de Chile. Correo electrónico: jphillips@uft.cl. Agradezco de manera especial los comentarios a borradores previos de este trabajo hechos por los profesores Jaime Arancibia, Alicia de la Cruz.

Camilo Mirosevic, Nancy Barra, Angélica Benavides Cristóbal Aguilera y Rodrigo Poyanco. También, le doy las gracias a la profesora Silvia Díez por su maravilloso libro sobre precedente administrativo, cuya lectura fue una gran inspiración para realizar este trabajo. Del mismo modo, agradezco las intervenciones de los alumnos del Magister en Derecho Administrativo de la Universidad de los Andes que asistieron al taller dedicado a este tema, especialmente las de Alejandro Valdés. Asimismo, le agradezco a Andrea Céspedes y a Nicolás Bucarey sus comentarios y sugerencias bibliográficas. Por último, muy agradecido estoy de las útiles críticas y comentarios de los revisores anónimos de este trabajo. Todos los posibles errores son de responsabilidad del autor.
}

Artículo recibido el 26 de febrero de 2020 y aceptado el 15 de mayo de 2020. 
aunque con un efecto general. En virtud de lo anterior, se propone una nueva forma de entender cómo opera la obligatoriedad del precedente contralor.

Palabras clave: precedente, obligatoriedad, Contraloría, ratio decidendi, obiter dicta. binding on sufficiently similar future cases. A different understanding of the CGR's case law bindingness is proposed.

Keywords: precedent, bindingness, Comptroller-General, ratio decidendi, obiter dicta.

\section{Introducción}

Se acepta en general que en los sistemas jurídicos de raíz continental el precedente judicial tiene solo efecto relativo, mientras que en la tradición del Common Law existe la denominada doctrina del stare decisis: los tribunales están obligados a "estarse a lo decidido" en sus decisiones pasadas. Y nuestro sistema, fiel a la tradición continental, dispone que "[l]as sentencias judiciales no tienen fuerza obligatoria sino respecto de las causas en que actualmente se pronunciaren"1.

Pero el sistema chileno es novedoso en cuanto al valor normativo de lo que se conoce como la "jurisprudencia" administrativa de la Contraloría General de la República (en adelante, CGR)². El artículo 6 de la Ley N 10.336 dispone que "solo las decisiones y dictámenes de la Contraloría General de la República serán los medios que podrán hacerse valer como constitutivos de la jurisprudencia administrativa" ${ }^{3}$. Y el artículo 19 de la misma ley establece: "[l]os abogados, fiscales o asesores jurídicos de las distintas oficinas de la Administración Pública o instituciones sometidas al control de la Contraloría que no tienen o no tengan a su cargo defensa judicial, quedarán sujetos a la dependencia técnica de la Contraloría, cuya jurisprudencia y resoluciones deberán ser observadas por esos funcionarios. El Contralor dictará las normas del servicio necesarias para hacer expedita esta disposición ${ }^{4 "}$.

Sobre la base de estas normas, aunque los pronunciamientos de la CGR son "obligatorios para los funcionarios correspondientes, en el caso o casos concretos a que se refieran" ${ }^{5}$, las decisiones de la CGR tienen un efecto obligatorio general para casos futuros, que es conceptualmente distinto de los efectos particulares de un pronunciamiento ${ }^{6}$.

Es cierto que en Chile y en otros ordenamientos ya se ha hablado de una obligatoriedad del precedente vinculada a la igualdad ante la ley y a la protección de la confianza‥ No obstante, el precedente de la CGR no obliga en

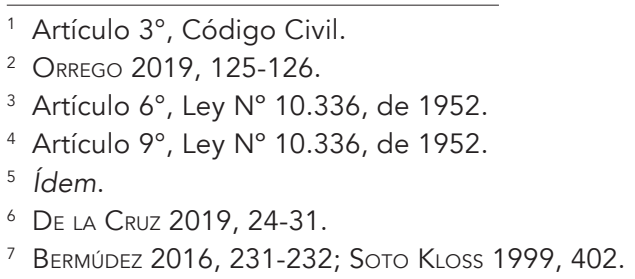


razón de otros principios, sino que cada decisión que compone el conjunto que denominamos "jurisprudencia administrativa" de la CGR sienta un precedente que es obligatorio para casos futuros por mandato legal ${ }^{8}$. Esto nos permite adscribir el precedente de la CGR a aquellos de carácter normativo, esto es, aquellos que fijan reglas que son consideradas como fuentes formales del derecho, como son los precedentes de los tribunales que pertenecen a la tradición del Common Law?.

Esta regla de stare decisis contenida en la Ley $N^{0} 10.336$ ha dado pie a ciertas críticas a la CGR. Por ejemplo, la han calificado como un organismo que se ubica "entre legislador positivo y juez activista"10. En efecto, una regla de precedente obligatorio sumado a los poderes que tiene para intervenir en diversos asuntos interpretando el ordenamiento jurídico-administrativo coloca a la CGR en una posición de especial preeminencia ${ }^{11}$. Incluso, en el desarrollo de este trabajo se han identificado fuertes tensiones entre el control de legalidad o juridicidad que realiza la CGR y su deber de no evaluar aspectos de mérito o conveniencia de las decisiones de órganos administrativos ${ }^{12}$.

En este contexto, el presente trabajo se propone analizar la normatividad del precedente de la CGR, es decir, cómo este precedente opera como una norma jurídica con efecto obligatorio. Se defenderá la hipótesis de que el precedente de CGR es similar a las leyes o reglamentos en cuanto tiene imperatividad general, pero que se diferencia de estos en que el precedente no asigna una consecuencia jurídica a un supuesto de hecho abstracto, sino que aplica un criterio jurídico en un supuesto concreto, que es posible extrapolar a otros casos semejantes por virtud de su imperatividad general. Esto con el objetivo de proponer una reinterpretación de la forma en que debe ser entendido el efecto obligatorio del precedente de la CGR y para determinar en qué condiciones se verifica tal obligatoriedad. De este modo, aunque sin duda es de gran relevancia, no se analizará el problema de la tensión entre control de legalidad y de mérito por exceder el propósito de este trabajo. Se asumirá que, en la actualidad, los sistemas jurídicos admiten que los órganos dotados de potestades resolutivas incorporen en su toma de decisiones valores como la dignidad, igualdad o la certeza ${ }^{13}$, a pesar de que tal premisa pueda ser discutida.

Para el logro de estos objetivos se utilizó de modo principal la metodología dogmática y jurisprudencial. Así, se analiza el contenido de las normas que establecen la obligatoriedad del precedente y de diversas normas jurídicas aplicadas por la CGR en distintos casos que fueron seleccionados al efecto. Esto para determinar en forma clara cómo ha sido entendida la regla de

\footnotetext{
8 Soto Kloss 1996, 37.

9 DIEZ 2008, 69-70.

10 Cordero 2010, 165. Ver también, De la Cruz 2019, 93-94.

11 De la Cruz 2019, 12-30.

12 Artículo 21 B, Ley No 10.336 de 1952.

13 OrRego 2009, 608.
} 
stare decisis de la Ley $N^{\circ} 10.336$. Pienso que para lograr los objetivos de este trabajo resulta más eficaz hacer una selección acotada de buenos casos. Ello, porque para mostrar cómo ha sido entendida la obligatoriedad del precedente de la CGR es necesario hacer un análisis detallado de las normas jurídicas y los hechos objeto de cada decisión. Así, de la multitud de casos existentes, se seleccionaron aquellos que resultaban de mayor interés por su complejidad o por haber existido pronunciamientos de los tribunales superiores de justicia.

El trabajo tiene la siguiente estructura. En un primer apartado se analizan las implicancias que tiene para nuestro ordenamiento y mentalidad jurídica la regla de stare decisis de la Ley $N^{\circ}$ 10.336. Esto permitirá establecer dos premisas que deben orientar la aplicación de un sistema de precedentes. Primero, se argumentará que los precedentes se asemejan a las leyes generales y abstractas ya que ambos tienen un efecto obligatorio general. Esta semejanza permitirá sostener la tesis de que es necesaria la publicación de los precedentes, no ya solo como una buena práctica, sino como una obligación jurídica. En segundo lugar, se argumentará que los precedentes, a diferencia de las leyes, no se refieren a supuestos abstractos, sino concretos. Sin pretender hacer un análisis comparado propiamente tal, esto justificará aplicar la distinción entre ratio decidendi y obiter dicta, que se suele usar en el Common Law, para determinar el contenido obligatorio de un precedente. En consecuencia, se sostendrá que no corresponde aplicarlos como si fuesen normas que regulan un supuesto abstracto.

En un segundo apartado se hará un análisis jurisprudencial de cómo ha sido aplicada la regla stare decisis de la Ley $N^{\circ} 10.336$. Siguiendo las premisas establecidas en la primera sección, primero, se mostrará cómo ciertos actos que no gozaron de publicidad general, han sido aplicados como precedentes. Frente a esto, se argumentará que es necesaria su publicación como ocurre con toda norma que goza de imperatividad general. Segundo, se observará que, en muchas oportunidades, los textos que conforman la jurisprudencia de la CGR han sido aplicados como si fuesen textos legales: se toma un texto que forma parte de un precedente y este es subsumido en un caso futuro. Esto será criticado porque así se infringe el deber de fundamentación del acto administrativo y, para subsanar esto, se sostendrá que es necesario prestar mayor atención a la base fáctica de los precedentes que se aplican, modifican o reconsideran.

\section{Una regla de stare decisis en un sistema de tradición continental}

El ya citado artículo 19 de la Ley No 10.336 establece que los órganos que conforman la Administración del Estado tienen el deber de observar la "jurisprudencia" de la CGR. Al respecto, un autor llega a la siguiente conclusión: "los dictámenes [de la CGR] tienden a ser generales y abstractos, a fin de que la interpretación de la ley que ellos contienen, esto es, la jurisprudencia administrativa, vincula no solo al órgano de la Administración o persona (funciona- 
rio o particular) respecto del que se emite, sino que a todos aquellos que se hallen en la misma situación"14.

La cita anterior describe con acierto el efecto obligatorio-general que tienen los dictámenes de la CGR. Pero es posible ahondar en este planteamiento haciendo algunas precisiones. Para esto, hay que considerar las dos características que se suelen asignar a las leyes para describir la forma en que operan como norma jurídica: su "generalidad" y su "abstracción".

Entiendo que las leyes son "generales" porque constituyen fuente formal del derecho y conforman el derecho vigente aplicable en una determinada sociedad, y son "abstractas" porque contienen una descripción normativa (supuesto de hecho) a la que se asigna una consecuencia jurídica. La jurisprudencia de la CGR es también norma general pues, por mandato del artículo 19 de la Ley $N^{\circ}$ 10.336, se integra en el conjunto de fuentes formales que regulan a los órganos administrativos. Pero no son abstractos al modo de las leyes, porque no contienen una descripción normativa que es aplicaba por subsunción a determinación hechos. Más bien, se refieren a un supuesto concreto que es aplicado a otros casos por ser considerandos en esencia iguales por la vía de una comparación.

De lo anterior, se puede concluir que un precedente obligatorio se parece a la ley en cuanto ambos gozan de imperatividad general, pero se distinguen en cuanto que el precedente se refiere a supuestos concretos y no abstractos. Cada una de estas características es importante para definir cuándo y qué contenidos de un precedente gozan de imperatividad general.

Así, a continuación, se argumentará que para el correcto funcionamiento del sistema de precedente obligatorio creado por la Ley $N^{\circ} 10.336$ hay que tener en cuenta dos premisas que derivan de las características señaladas. Primero, de la imperatividad general de los precedentes deriva la necesidad de su publicidad. Segundo, del hecho de referirse a supuestos concretos deriva la necesidad de determinar cuál es la ratio decidendi de cada pronunciamiento.

\section{La imperatividad general de los precedentes y su necesaria publicidad}

La CGR actúa mediante diversos tipos de actos: dictámenes, toma de razón, oficios de representación, informes de auditoría, entre otros. Frente a esto, es legítimo preguntarse qué actos conforman la jurisprudencia administrativa, ya que no todos tienen la misma naturaleza. Al respecto, el texto de las normas pertinentes tiene un amplio alcance. El artículo $6^{\circ}$ de la Ley $N^{\circ} 10.336$ habla de "decisiones y dictámenes" y el artículo 19 utiliza los conceptos de "jurisprudencia y resoluciones".

De estas normas se deriva que los actos que conforman la jurisprudencia administrativa (que tiene efecto vinculante-general) son, por regla general, pronunciamientos de efectos particulares. Lo anterior pone de relieve un

14 RomÁn 2018, 409-410. El énfasis es del autor citado. 
interesante problema relativo a la publicidad de los precedentes. Como ya se señaló, los precedentes son distintos a las leyes en cuanto se refieren a supuestos concretos, que pueden ser extrapolados a otros casos lo suficientemente similares. Sin embargo, se parecen a las leyes en que tienen un efecto normativo general.

Siempre ha existido una gran preocupación por dar publicidad a las decisiones de los tribunales en los sistemas del Common Law ${ }^{15}$. Pienso que lo anterior es importante porque, si estas decisiones van a imperar con efectos generales, deben recibir una adecuada publicidad para ser conocidas por sus destinatarios. Incluso, una autora señala que la publicación ordenada de los precedentes "es esencial para poder mantener un sistema mínimo de precedente"16. Y, si hacemos un análisis en paralelo con la legislación, la publicidad de las normas jurídicas es vista como una necesidad elemental de certeza jurídica $^{17}$, e incluso como un elemento esencial necesario para que una norma jurídica sea tal ${ }^{18}$. Por lo tanto, si un precedente va a tener eficacia general, es necesaria su publicación.

Esto pone de relieve la importancia de que la CGR dé, en forma activa, publicidad general a todas las decisiones que conforman la jurisprudencia administrativa. De este modo, que la CGR ponga a disposición del público un buscador de jurisprudencia ${ }^{19}$ no es solo una buena práctica: es una herramienta necesaria para satisfacer una exigencia elemental de seguridad jurídica, en consonancia con el artículo 16 de la Ley $N^{\circ} 19.880$.

\section{La ratio decidendi de un precedente: entre la norma y los hechos}

La mentalidad jurídica continental nos entrega herramientas para entender de modo claro la distinción entre los hechos y el derecho: las fuentes formales constituyen el derecho que es aplicado a las situaciones concretas que se presentan. En este contexto, un precedente no es ni una norma ni un hecho, sino que es el lugar de encuentro entre ambos. Por esto, una norma contenida en un precedente no es exactamente lo mismo que la norma vinculada a un supuesto abstracto.

En aquellos sistemas en que la jurisprudencia de los tribunales constituye una fuente formal directa del derecho se sostiene que no es correcto tratar las frases y oraciones de una sentencia como si fuesen un instrumento legislativo, esto es, leyes generales y abstractas ${ }^{20}$. Una parte importante de la formación de los abogados en esta tradición consiste en distinguir en cada fallo la ratio decidendi (en forma literal, "razón para decidir") de otros contenidos que denominan obiter dicta ("dicho sea de paso" o "by the way"). Ratio decidendi

15 Williams 2013, 30-32.

16 DIEZZ 2008, 265.

17 ÁviLA 2016, 208-210.

18 OrRego 2019, 110.

19 https://www.contraloria.cl/web/cgr/buscar-jurisprudencia2

20 Cross y Harris 2004, 95 y 179-180. 
es la regla de derecho conforme con la cual se realiza un pronunciamiento teniendo en cuenta todos los hechos materialmente relevantes del caso. Por su parte, obiter dicta son aquellas aseveraciones o consideraciones hechas "a mayor abundamiento". Estos contenidos no determinan la decisión tomada ${ }^{21}$.

Lo que busca un sistema de precedente obligatorio es que casos con un sustrato fáctico similar sean resueltos utilizando los mismos razonamientos jurídicos, protegiendo así la igualdad ante la ley ${ }^{22}$. En consecuencia, en este tipo de sistemas, solo la ratio decidendi de un pronunciamiento obligatorio debe ser observada en casos futuros. Mientras tanto, los contenidos denominados obiter dicta, que no tienen relación con los hechos relevantes del caso o no determinan la decisión tomada, no constituyen reglas obligatorias para casos futuros.

Determinarla la ratio en cada caso es un asunto complejo no exento de discusiones ${ }^{23}$. Reglas de obligatoriedad del precedente como esta buscan proteger la igualdad ante la ley. Un conocido manual inglés señala que "es un principio básico de la administración de justicia que los casos semejantes deben ser resueltos de modo semejante"24. De este modo, al aplicar una regla de stare decisis, es necesario mirar más allá de lo dicho en cada pronunciamiento y mirar de cerca los hechos sobre los cuales recayó la decisión.

Los sistemas continentales como el nuestro no tienen la misma preocupación por distinguir la ratio decidendi de un fallo, pues la jurisprudencia solo tiene efecto relativo ${ }^{25}$. Por esto, la aplicación de la regla de stare decisis de la jurisprudencia de la CGR tiene problemas cuya raíz es cultural. Nuestra mentalidad continental nos ha llevado en muchas oportunidades a aplicar los precedentes de la CGR como si fuesen leyes: recogemos un determinado texto contenido en un pronunciamiento de la CGR y lo subsumimos a los hechos de un caso futuro.

Sin embargo, lo anterior no es correcto por dos razones. Primero, porque el artículo 19 de la Ley $N^{\circ} 10.336$ habla de un deber de "observar" la "jurisprudencia" de la CGR. La voz jurisprudencia hace referencia a una realidad que tiene dos elementos: un conjunto de decisiones y unos hechos sobre los que recae cada decisión. Por esto, lo que hay que "observar", según el artículo 19, es la decisión tomada en un determinado caso, cuando se presenta otro semejante. De esta manera, tomar el texto de un informe de la CGR y aplicarlo a un caso futuro sin ninguna referencia a los hechos concretos que lo motivaron es una práctica que tergiversa el mandato del citado artículo 19.

\footnotetext{
21 Williams 2013, 105-107.

22 ÁvILA 2016, 335.

23 lbíd., 95-96.

24 CROSS y HARRIS 2004, 3. La traducción es propia.

25 Ibíd., 49. Con todo, tanto en el Common Law como en sistemas continentales, existe el problema de los constantes cambios de criterio de los tribunales superiores. Al respecto, ver VERGARA 2019, 18-20, y CROSS y HARRIS 2004, 93.
} 
En segundo lugar, los textos que conforman la jurisprudencia de la CGR no deben ser aplicados como leyes porque solo le corresponde al legislador "explicar o interpretar la ley de un modo generalmente obligatorio"26. Pienso la CGR no tiene una potestad que le permita, en general, interpretar todo el ordenamiento jurídico administrativo con efectos generales y de un modo abstracto. Esto por dos razones. Primero porque, aunque las materias sobre las que se puede ejercer la potestad dictaminante son bastantes amplias, la ley es cuidadosa al señalar que la CGR se puede pronunciar sobre "asuntos" referidos a las distintas materias que enumera ${ }^{27}$. Esto concuerda con el hecho de que es la "jurisprudencia" de la CGR lo que debe ser obedecido por otros órganos, esto es, decisiones referidas a casos concretos. Por otro lado, la potestad de informar de la CGR se hace por medio de dictámenes, que son opiniones jurídicas respecto de casos $\operatorname{concretos}^{28}$. Esto no impide que la ley le otorgue, respecto de ciertas materias, a la CGR la potestad de dictar normas de efectos generales ni le impida ejercer su potestad dictaminante de oficio. Al contrario, ello sí es posible, pero de ello no se desprender que la potestad dictaminante o de informar que tiene la CGR respecto de variados asuntos esté concebida como de aquellas para interpretar todo el ordenamiento administrativo de un modo abstracto y general.

Segundo, porque cuando el legislador ha entregado la potestad de interpretar la ley de un modo abstracto y con efecto general, atribuye la potestad de "interpretar administrativamente" la ley ${ }^{29}$, que es distinta de la potestad para pronunciarse sobre "asuntos" referidos a diversas materias, por amplia que sea la competencia para ello.

De este modo, difiero de la opinión de que la CGR puede ejercer sus potestades respecto de supuestos abstractos, lo que sí pueden hacer otros organismos que tienen la potestad para "interpretar administrativamente" leyes o reglamentos ${ }^{30}$. Además, así lo ha entendido históricamente la CGR. Un interesante trabajo recoge un pronunciamiento de 1946 en que el contralor Mewes se negó a dar respuesta a una consulta "meramente informativa", formulada por un particular respecto del derecho a percibir una asignación profesional. En esa oportunidad, el contralor resolvió que no le correspondía pronunciarse porque la consulta que no se refería a ninguna situación real en particular ${ }^{31}$.

\footnotetext{
26 Artículo $3^{\circ}$, Código Civil.

27 Por ejemplo, ver artículos $5^{\circ}$ y 6, Ley N 10.336 de 1952.

28 Soto KLOSS (2012), p. 791-801.

29 Por ejemplo, ver artículo $6^{\circ}$, letra A, No 1, Código Tributario; artículo 5, Decreto Ley $N^{\circ} 3538$ de 1980; artículo $3^{\circ} N^{\circ} 34$, Ley $N^{\circ} 18.410$ de 1985. Otros ejemplos de leyes que regulan este tema en GUZMÁn BrITO (2019), pp. 37-39

30 GuZMÁn BRITo (2019), p. 111. También se podría sostener que nadie goza de legitimación para hacer ese tipo de consultas porque carece del interés necesario para ingresar a un procedimiento administrativo (artículo 21, Ley $N^{\circ} 19.880$, de 2003), o porque no tendría ningún propósito que la CGR ejerza sus potestades de control en situaciones hipotéticas.

31 De La CRuz 2019, 54.
} 
Lo anterior no significa que el precedente de la CGR sea obligatorio por el hecho de ser "jurisprudencia", como ocurre en los países anglosajones con los precedentes judiciales, sino que obliga por mandato del artículo 19 de la Ley $N^{\circ}$ 10.336. Pero si examinamos el texto del artículo citado vemos que los órganos de la Administración no solo deben observar las "resoluciones" de la CGR (actos de efectos particulares) sino que también la "jurisprudencia", esto es, decisiones pasadas recaídas sobre determinados hechos también pasados. Esto hace que la normatividad (su modo de operar como norma jurídica) de la jurisprudencia de la CGR sea bastante distinta a la de las leyes. Su contenido obligatorio no depende solo de las palabras y la descripción normativa utilizada por la autoridad, esto es, el texto del pronunciamiento: también depende del hecho concreto a que se refiere el caso.

Teniendo en cuenta lo dicho hasta ahora, pienso que la distinción entre ratio decidendi y obiter dicta utilizada en el Common Law debiese ser extrapolada para aplicar las reglas de los artículos 6 y 19 de la Ley $N^{\circ} 10.336$ de 1952. Esto porque los mencionados conceptos permiten determinar el contenido obligatorio de un precedente teniendo en cuenta tanto el texto del pronunciamiento como los hechos sobre los que este recayó. Así, pienso que son una herramienta idónea para aplicar la regla de obligatoriedad del precedente de la CGR.

Se podría criticar esta aproximación como un intento de utilizar una doctrina foránea que no cuadra bien con nuestro sistema. Asimismo, se podría argumentar que existen otras doctrinas referidas a la obligatoriedad del precedente, como la de la autovinculación alemana. Esta doctrina consiste en que, con apoyo en los principios de igualdad ante la ley y la protección de la confianza, la Administración estaría vinculada a seguir sus actuaciones precedentes y, para efectos de este trabajo, podría pensarse que tiene la doble ventaja de estar inserta en un sistema continental y está referida al precedente administrativo ${ }^{32}$.

Estas críticas, sin embargo, pueden ser descartadas. Si bien es cierto que la distinción que se pretende aplicar proviene de un sistema ajeno al nuestro, tampoco deja de ser cierto que todos los sistemas de stare decisis tienen elementos comunes ${ }^{33}$. Por esto, resulta útil acudir a las herramientas de otra tradición, más versada en este tipo de reglas, para aplicar en forma racional nuestras propias reglas que consagran la obligatoriedad del precedente. Por otro lado, respecto de la doctrina de la autovinculación alemana, he descartado acudir a ella para abordar el caso de la jurisprudencia de la CGR porque existe un rasgo esencial que las hace distintas. En el caso alemán, la autovinculación al precedente administrativo se construye sobre la base de la

\footnotetext{
32 DIEZ 2008, 181-191, 201.
}

33 Ibíd., 111. 
igualdad ante la ley. Así, hay una obligatoriedad indirecta del precedente, a diferencia del precedente de CGR donde existe una obligatoriedad directa ${ }^{34}$.

\section{La aplicación del precedente de la CGR: críticas y propuestas}

Lo dicho hasta ahora ha permitido mostrar que los precedentes tienen elementos comunes con las normas generales y abstractas, aunque tienen diferencias. Estos tienen un efecto obligatorio general similar al de la legislación y reglamentos, lo que ha permitido argumentar que es necesario darles una adecuada publicidad. También, se ha asentado que del hecho de que los precedentes sean pronunciamientos se deriva que no pueden ser aplicados del mismo modo que las leyes.

Teniendo en cuenta lo anterior, en esta sección, se mostrará que los precedentes de la CGR han sido aplicados sin considerar las dos reglas básicas establecidas en la sección anterior para la correcta operatividad de un sistema de precedentes, esto es, que son aplicados como normas con un efecto imperativo general, pero sin recibir la publicidad que reciben las leyes, y que son aplicados como si fuesen normas referidas a supuestos abstractos cuando, en realidad, se refieren a supuestos concretos extrapolables a otros casos semejantes. Esto será sometido a críticas y se propondrán soluciones acordes con las premisas elaboradas en la primera sección.

1. La falta de publicidad de los precedentes de la CGR

En general, la CGR suele publicar las decisiones que considera como precedente obligatorio en su portal web ${ }^{35}$. Se trata de una herramienta de gran utilidad para autoridades públicas sometidas a la fiscalización de la CGR y para quienes se relacionan con la Administración. Con todo, en es trabajo se ha mostrado que la publicación de precedentes que van a tener un efecto general no es solo una buena práctica, sino que es un imperativo jurídico. No obstante, en ocasiones, la CGR ha invocado como precedente pronunciamientos que no recibieron una publicidad adecuada.

Un ejemplo de lo anterior se puede encontrar en el Dictamen N²5.534 de 2019. En esa oportunidad, la CGR se pronunció sobre los efectos en el tiempo del Dictamen N $N^{\circ} 16.587$ de 2019 que interpretó el artículo 18 bis E de la Ley $N^{\circ}$ 19.039. En resumen, el caso consistía en lo siguiente. El artículo citado establece que el solicitante de una patente debe acreditar el pago de ciertos derechos ante el Departamento de Propiedad Industrial del Instituto de Propiedad Intelectual (INAPI) en el plazo de 60 días desde que queda ejecutoriada la resolución que autoriza la inscripción de una patente de invención. De no cumplir con esta exigencia, la solicitud se entiende abandonada y se procede a su archivo, perdiendo, por consiguiente, su prioridad. No obstante, el artículo 45 de la Ley No 19.039 establece que, tratándose de exigen-

\footnotetext{
34 Ibíd., 246.

35 https://www.contraloria.cl/web/cgr/buscar-jurisprudencia2.
} 
cias de tramitación, es posible obtener el desarchivo de las solicitudes (y, por tanto, no perder la prioridad), siempre que la exigencia respectiva sea subsanada dentro de los 120 días subsiguientes a la declaración de abandono.

Esto suscitó la discusión de si el pago de los derechos de que habla el artículo 18 bis E constituía o no una "exigencia de tramitación". Antes del año 2005, el INAPI consideraba que el no pago de los derechos exigidos por la normativa era una exigencia de tramitación que podía ser subsanada. Por esto, en la práctica, se aceptaban pagos fuera del plazo de 60 días establecido en el artículo 18 bis E con fundamento en el artículo 45. Tal proceder fue cuestionado por el informe de auditoría No 191 de 2005 de la CGR, donde se señaló que el pago de los derechos no podía ser una exigencia de tramitación, pues el procedimiento ya se encontraba finalizado. En consecuencia, vencido el plazo de 60 días, la solicitud debía ser tenida por abandonada en forma definitiva. Y, por esta razón, la autoridad dictó una circular acoplándose al criterio del mencionado informe.

Años después, varios particulares solicitaron un pronunciamiento de la CGR para que revisara la legalidad de tal circular del INAPI, porque consideraban que el pago de los derechos sí era una exigencia de tramitación. Estas presentaciones dieron lugar al Dictamen N 16.587 de 2019 que declaró que el pago de los derechos sí era una exigencia de tramitación y que, por tanto, era aplicable en ese caso el artículo 45 de la Ley $N^{\circ} 19.039$.

Con todo, el INAPI hizo una presentación ante la CGR señalando que ellos mismos, por medio del informe de auditoría $N^{\circ} 191$, les habían ordenado no considerar el pago de los derechos como una exigencia de tramitación. Esta solicitud dio origen al Dictamen N²5.534 de 2019. Este declaró que el Dictamen $N^{\circ} 16.587$ no podía tener efecto retroactivo porque implicó un cambio de criterio respecto del informe de auditoría emitido el año 2005. De este modo, el nuevo criterio no alcanzaría a las solicitudes ya declaradas como abandonadas antes del Dictamen $N^{\circ} 16.587$ de 2019, salvo aquellas que dieron origen al cambio de criterio.

El pronunciamiento sobre la irretroactividad del Dictamen $N^{\circ} 16.587$ plantea un problema interesante. La jurisprudencia de CGR ha señalado que sus dictámenes, se entienden incorporados a las leyes interpretadas, no rigiendo para ellos el artículo 52 de la Ley $\mathrm{N}^{\circ} 19.880^{36}$. Se trata de actos declarativos-interpretativos que tienen por naturaleza efecto retroactivo ${ }^{37}$. No obstante, la misma CGR ha entendido que, una vez fijada su jurisprudencia respecto de un determinado punto, la decisión de modificarla no puede tener efecto retroactivo ${ }^{38}$.

Con lo anterior, la excepción de irretroactividad es procedente cuando la CGR modifica su jurisprudencia ya establecida. De este modo, lo que hay

\footnotetext{
36 Dictamen N 50.185 (2007).

37 Madariaga 1993, 181.

38 Por ejemplo, ver Dictamen No 14.292 (2007); Dictamen Nº 40.086 (2015).
} 
que resolver es si el informe de auditoría $N^{\circ} 191$ era un precedente generalmente obligatorio. Pienso que el mencionado informe no es un precedente obligatorio, porque este no puede ser encontrado en la base jurisprudencial de la CGR ni tampoco recibió publicidad general. Al respecto, la única que adoptó fue aquella propia de los actos de efectos particulares, esto es, la notificación a los interesados. En consecuencia, solo conocían ese pronunciamiento la CGR y el INAPI.

De esta manera, es posible cuestionar que dicho informe haya sido considerado un precedente obligatorio con el propósito de limitar el efecto declarativo del Dictamen $N^{\circ} 16.587$ de 2019. En efecto, iría en contra del artículo 16 de la Ley $N^{\circ} 19.880$ que la CGR elabore una especie de jurisprudencia "secreta" mediante informes que solo conoce ella y los órganos de la Administración activa. De todas formas, aunque los particulares no están formalmente obligados a seguir el precedente de la CGR, sí tiene un relevante impacto indirecto sobre ellos. Por lo tanto, lo lógico que es un pronunciamiento que va a ser norma obligatoria y general para casos futuros (o para aplicar la excepción de irretroactividad del cambio de jurisprudencia) y sus fundamentos sean objeto de una adecuada publicidad para garantizar que todos los órganos administrativos y los particulares que se relacionan con ellos los conozcan.

Podría argumentarse en contra de esta posición que admitir el efecto retroactivo del Dictamen $N^{\circ} 16.587$ tendría un resultado devastador al permitir la revisión de procedimientos archivados años atrás. Sin embargo, esta posición puede ser descartada. Primero, porque este efecto declarativo-retroactivo es el que generalmente se acepta para los actos de contenido interpretativo. Por esto, quien sostenga esto, debiese dar razones para descartar del todo el efecto retroactivo de todos los actos de interpretación, que es la opinión predominante ${ }^{39}$. Segundo, aunque la circular haya sido declarada antijurídica, ello no implica revisar todas las decisiones tomadas en el pasado en virtud de ella. En efecto, la existencia de situaciones jurídica consolidadas podría servir como límite a los efectos retroactivos de esa declaración ${ }^{40}$. Así, en lugar de descartar de plano la posibilidad de controlar las decisiones tomadas en virtud de la circular declarada ilegal, se podría admitir su revisión en caso de que no existan situaciones jurídicas consolidadas sobre la base de una confianza protegible.

El problema de la falta de publicidad de los precedentes también se puede ver en un pronunciamiento de la Corte Suprema, precisamente en la causa "Abufrut Limitada con Servicio Agrícola y Ganadero (SAG) y Fisco de Chile". Con fecha 5 de octubre de 1990 se publicó en el Diario Oficial el Decreto 143 de Ministerio de Agricultura, que fijó las tarifas que podía cobrar el SAG por ciertas inspecciones que tenía que realizar. Tal decreto fue tomado

\footnotetext{
39 VALDIVIA 2018, 198.

40 Millar 2012, 421-423; Boettiger 2009, 317-320. Ver también, Letelier 2014, 627-631.
} 
de razón por la CGR. En forma posterior, la CGR se pronunció sobre la legalidad del referido decreto y declaró que el SAG tenía que financiar con cargo al presupuesto respectivo aquellas inspecciones que tenía que realizar de oficio. Por esto, se ordenó efectuar las modificaciones pertinentes al decreto de tarifas "en cuanto dicho acto administrativo hubiere incluido costos que, conforme a lo anteriormente señalado, no ha correspondido considerar al efecto" 41 .

Teniendo en cuenta este pronunciamiento, se interpuso una demanda por pago de lo no debido e indemnización de perjuicios en contra del SAG y el Fisco de Chile por haber hecho unos cobros sin potestad legal para ello y que no tenían título para retener. En efecto, del dictamen de la CGR parecía desprenderse que el decreto de tarifas era ilegal y, consecuencialmente, los cobros hechos en virtud del mismo también lo eran. Sin embargo, la Corte Suprema decidió acoger una casación de la defensa fiscal y rechazar la demanda. Sostuvo que la jurisprudencia vigente de la CGR hasta el año 2007 consistía en que el decreto se ajustaba a derecho. Luego, el Dictamen No 18.390 de 2007 solo era un cambio de criterio respecto del oficio que tomó razón del decreto de tarifas. Por lo tanto, este no podía ser aplicado con efecto retroactivo ni tampoco implicó una declaración de nulidad del decreto o una orden de devolver las sumas percibidas en forma ilegal: solo se ordenó modificar el reglamento hacia el futuro de manera que el SAG financiara por cargo al presupuesto las inspecciones que debía realizar de oficio ${ }^{42}$.

Esta decisión puede ser criticada. Se puede admitir que la CGR no declaró la nulidad del reglamento en forma expresa ni ordenó al SAG restituir las sumas percibidas en forma ilegal. No obstante, del pronunciamiento se desprende en forma clara que el decreto era ilegal. De esta manera, en principio, nada impedía entender que este era nulo ab initio y que el demandante podía recuperar las sumas pagadas dentro de los plazos de prescripción. Sin embargo, la Corte Suprema opta por otra solución, pues entiende que la toma de razón del reglamento era un precedente anterior que la CGR no podía modificar con efecto retroactivo.

Con todo, si se considera el análisis que se ha hecho sobre la necesidad de publicar los precedentes, es posible rechazar esta interpretación. Si a un precedente se le va a atribuir un efecto normativo-general es necesario que esté publicado, para asegurar su conocimiento ciudadano. No obstante, el oficio de toma de razón, en este caso, es solo conocido por la CGR, el Ministerio de Agricultura y el SAG. Por otro lado, tampoco se conocen las razones por las que se decidió tomar razón del referido reglamento, si es que alguna se expresó en el oficio respectivo. Apoya esta interpretación el hecho de que la misma CGR no tuvo en cuenta su propia toma de razón en el dictamen de

\footnotetext{
41 Dictamen $N^{\circ} 18.390$ (2007).

42 Abufrut Limitada con SAG y Fisco de Chile (2015), considerando 17. Ver también, Aserraderos Mininco S.A. con SAG (2013).
} 
2007, en el que no se hace mención del precedente que la Corte Suprema entendió que se estaba reconsiderando ${ }^{43}$.

A pesar de lo anterior, la Corte Suprema entiende que un oficio de toma de razón sí es un precedente obligatorio que limita el efecto declarativo-retroactivo de un dictamen posterior. Y lo mismo hace la CGR en el primer caso analizado respecto de un informe de auditoría ${ }^{44}$. Pienso que nada impide considerar a estos actos de efectos particulares, del mismo modo que se hace con los dictámenes como precedentes obligatorios ${ }^{45}$. Sin embargo, para que estos hechos valgan como tales, es necesaria su publicación como elemento esencial requerido para la vigencia de toda norma jurídica y para garantizar el conocimiento ciudadano de su contenido.

\section{El precedente utilizado como norma general y abstracta}

En sus pronunciamientos, la CGR suele utilizar distintos verbos para referirse a sus propios precedentes. Utiliza el verbo "aplica" se pronuncia siguiendo lo establecido por un precedente, mientras utiliza el verbo "reconsidera" cuando entiende abandonar un criterio utilizado en el pasado. Asimismo, como se verá, se utilizan los verbos "complementa" o "aclara" cuando se quiere añadir algo al precedente (por incompleto o dudoso), sin que ello sea incompatible con lo decidido en el pasado.

Los verbos mencionados son importantes pues reflejan qué precedentes la CGR considera como obligatorios e indican cuando un precedente es abandonado o modificado por una decisión sobreviniente. En muchas situaciones estos verbos son utilizados solamente teniendo en cuenta el texto de un determinado pronunciamiento, sin reparar en los hechos que lo motivaron. Lo anterior, de acuerdo con la segunda premisa establecida en la primera sección, es un error pues las palabras de un informe de la CGR no pueden ser tratadas como si fuesen normas generales y abstractas.

Esto no es solo un problema teórico, sino que tiene una importante consecuencia práctica. La falta de consideración de la base fáctica de un precedente ya sea para aplicarlo, aclararlo o reconsiderarlo, puede generar un grave vicio de falta de fundamentación en un determinado pronunciamiento. Esto ha sido detectado en algunos casos por la Corte Suprema, pero en otros no. Por esto, a continuación, se analizarán tres situaciones en que el precedente de la CGR es utilizado como norma general y abstracta, donde se incurre en el problema señalado. En cada caso, se propondrán soluciones para arreglar el problema.

43 Dictamen $N^{\circ} 18.390$ (2007).

44 Dictamen $N^{\circ} 25.534$ (2019).

45 Por ejemplo, ver Dictamen Nº5.125 (2009). 
a) Alcance del efecto obligatorio: la ratio decidendi y los hechos materialmente relevantes

La CGR suele "aplicar" (y así lo declara) sus dictámenes en situaciones que muchas veces guardan poca semejanza, o también muchas autoridades administrativas se creen obligadas por un pronunciamiento solo por el hecho de estar contenido en un informe de la CGR, sin hacer un análisis de los hechos materialmente relevantes y la regla recaída sobre ellos.

Para ilustrar lo anterior se puede considerar el conflicto desatado por la llamada objeción de conciencia institucional creada por la Ley N²1.030 de 2017, que reguló el aborto en tres causales. Luego de la intervención del Tribunal Constitucional en control preventivo, el nuevo artículo 119 ter del Código Sanitario terminó señalado lo siguiente: "La objeción de conciencia es de carácter personal y podrá ser invocada por una institución", en circunstancias que el proyecto original señalaba que la objeción de conciencia "en caso alguno podrá ser invocada por una institución"46.

Con lo anterior, y por medio de la Resolución Exenta N 423 del Ministerio de Salud, se dispuso a regular la forma de ejercer la objeción de conciencia. En tal acto administrativo se permitió que instituciones privadas, a pesar de tener convenios vigentes con el Ministerio de Salud, pudieran hacer uso de la objeción de conciencia. Esto fue resistido por un grupo de parlamentarios porque consideraron que restringía en forma antijurídica la operatividad de la Ley $N^{\circ} 21.030$, por lo que solicitaron un pronunciamiento de la CGR.

La solicitud mencionada dio lugar al Dictamen $N^{0} 11.781$ de 2018. En tal pronunciamiento, la CGR ordenó al Ministro de Salud tomar las medidas necesarias para dejar sin efecto la resolución objeto de la solicitud, por ser esta contraria a derecho. Esto por dos razones. Primero, declaró que la resolución, por contener reglas generales y abstractas destinadas a complementar la regulación legal, tenía las características de un reglamento presidencial sin cumplir con las formalidades necesarias para ello. Segundo, teniendo en cuenta que a los organismos públicos no les está permitido hacer objeción de conciencia, se sostuvo que las instituciones privadas que tengan convenios con el Ministerio de Salud tampoco pueden hacerlo dado que sustituyen a los Servicios de Salud en la ejecución de las acciones destinadas a la protección o recuperación de la salud ${ }^{47}$.

Desde el punto de vista de la obligatoriedad del precedente, la decisión de la CGR tiene dos problemas. Primero, para sostener su primer argumento, el órgano de control declara "aplicar" el Dictamen Nº 97.773 de 2014. En tal pronunciamiento también se objetó una resolución del Ministerio de Salud, organismo que emitió una resolución exenta por medio de una delegación de firma presidencial (esto es, "por orden del presidente de la República").

\footnotetext{
46 Sentencia TC Rol No 3729 (2017).

47 Dictamen $N^{\circ} 11.781$ (2018).
} 
Esto fue considerado antijurídico por ser la potestad reglamentaria presidencial indelegable ${ }^{48}$.

Pero en el caso analizado en el Dictamen N 11.781 de 2018 la situación era distinta. En esa oportunidad, se cuestionó la aplicación que el Ministerio hizo de sus potestades contenidas en el artículo $4^{\circ} \mathrm{N}^{\circ} 14$ del Decreto con Fuerza de Ley $N^{\circ} 1$ de 2005 de Ministerio de Salud y del mandato contenido en el nuevo artículo 119 ter del Código Sanitario en orden a regular cómo hacer operativa la objeción de conciencia. Esto es distinto a la situación de la delegación de firma: una cosa es sostener que una potestad es indelegable y otra es que por medio del ejercicio de otras potestades no se deba invadir el ámbito de uso de otras. Por tanto, es difícil sostener que el Dictamen N 97.773 de 2014 fue un precedente que obligó a la CGR a dar un determinado contenido al Dictamen No 11.781 de 2018.

Algo similar puede decirse respecto del precedente invocado por la CGR para defender el segundo argumento. Tal precedente es el Dictamen N 44.822 de 2011. En dicho informe, la CGR resolvió que al Hospital Clínico de la Universidad de Chile sí le eran aplicables los procedimientos de mediación previstos en la Ley $N^{\circ}$ 19.966. Esto porque el mencionado hospital formaba parte de la estructura orgánica de la Universidad de Chile y porque tenía convenios vigentes con el Ministerio de Salud para atender las necesidades de salud de la población.

Este precedente fue "aplicado" para sostener que todas las instituciones privadas que tuvieran convenios con el Ministerio de Salud "sustituían" al Estado en sus obligaciones, y, por lo tanto, no podían hacer valer una objeción de conciencia institucional. Pero ello parece excesivo si se considera que el precedente invocado solo resolvió que un hospital que tuviese convenios con el Ministerio de Salud le era aplicable el procedimiento de mediación previsto en la Ley $\mathrm{N}^{\circ}$ 19.966. Lo anterior poca relación tiene con que quienes tengan convenios con el Ministerio de Salud asuman la posición del Estado y, en consecuencia, vean limitada su libertad de conciencia.

Considerando lo anterior, es posible advertir que el verbo "aplicar" se utiliza indistintamente en dos hipótesis que son distintas. Por un lado, en unos casos se aplica un precedente para resolver casos en esencia iguales. Por el otro, se recoge un criterio jurídico contenido en un determinado caso, para aplicarlo por analogía en otro que es, sin embargo, distinto. En la primera situación la CGR está en principio obligada a seguir su precedente, mientras que no es así en la segunda.

Lo anterior tiene una importante consecuencia desde el punto de vista de la fundamentación del acto administrativo ${ }^{49}$. En aquellos casos en que genuinamente se aplica un precedente, por tratarse de casos en esencia igua-

\footnotetext{
48 Dictamen $\mathrm{N}^{\circ} 97.773$ (2014).

49 Artículos 11 y 41, Ley Nº 19.880 de 2003.
} 
les, bastaría como fundamentación invocar el precedente, pues con ello se entiende que la CGR está indicando que el caso que ahora resuelve es idéntico al anterior. Pero cuando la CGR "aplica" un precedente para resolver un caso cuya base fáctica es distinta, lo que hace la CGR es soslayar su deber de fundamentación porque la decisión, en definitiva, no explica por qué casos con hechos distintos deben ser resueltos con el mismo criterio: en tal acto se omite la fundamentación fáctica ${ }^{50}$.

Por esto, sería conveniente que la CGR utilice un lenguaje más preciso. Con el verbo "aplicar" se podría designar aquellas situaciones en que la CGR sigue el precedente sentado en casos pasados en esencia iguales. Mientras tanto, podría utilizar el verbo "considera" para referirse a aquellos precedentes que, sin estar referidos a casos en esencia iguales, contienen un criterio jurídico que es útil para tomar una decisión en el presente. Pero en ese segundo caso, la CGR debe explicitar por qué, a pesar de las diferencias fácticas, de todos modos, lo correcto es aplicar el mismo criterio.

Un segundo problema tiene que ver con la formulación de la regla de precedente establecida por el Dictamen N 11.781 de 2018. Emitido dicho dictamen, el presidente emitió un decreto supremo corrigiendo los problemas que adolecía la resolución del Ministerio de Salud. Ahí se señaló que las instituciones privadas que tuviesen convenios con el Ministerio de Salud no podrán ser objetoras de conciencia cuando tales convenios tuviesen por objeto prestaciones de obstetricia y ginecología ${ }^{51}$. En estas circunstancias, se puede decir que el presidente entendió que el Dictamen $N^{\circ} 11.781$ era un precedente obligatorio en sus dos sentidos: en cuanto a la necesidad de un decreto supremo reglamentario para regular tal materia y en relación con la posibilidad de que instituciones privadas hicieran objeción de conciencia.

No obstante, a la luz de lo expuesto hasta ahora, pienso que es posible cuestionar que la regla de la sustitución formulada en el Dictamen N ${ }^{\circ} 11.781$ de 2018 haya sido un precedente con carácter obligatorio, como sí lo entendió la CGR al desarrollar en forma posterior el alcance de la regla de la sustitución ${ }^{52}$. Pienso que tal regla no forma parte de la ratio decidendi de dicho pronunciamiento. Ello porque el hecho de que la resolución exenta que fue declarada contraria a derecho haya permitido a las instituciones privadas con convenios hacer objeción de conciencia no es determinante para la decisión adoptada.

Si se considera el primer argumento esgrimido por la CGR, se puede señalar que ese dictamen asentó como precedente la siguiente regla: la au-

\footnotetext{
50 Sobre la fundamentación fáctica del acto administrativo, en nuestro medio, Soto Kloss (2012), pp. 430-432.

51 Artículo 13, Decreto Supremo No 67 de 2018. Este artículo luego fue declarado contrario a la Constitución por la Sentencia TC Rol N 5572 (2018). A pesar de lo anterior, lo importante para este trabajo es en qué medida el presidente se creyó obligado a seguir el argumento de la sustitución contenido en el Dictamen Nº 11.781 (2018).

52 Dictamen No24.216 (2018).
} 
toridad administrativa no puede por medio de una resolución exenta dictar preceptos generales y abstractos destinados a complementar el contenido de una ley, porque ello forma parte de la potestad reglamentaria de ejecución radicada en forma exclusiva por la Constitución en el presidente de la República. En consecuencia, la resolución exenta fue declarada inconstitucional por no ser el vehículo jurídico idóneo para tomar una decisión de esa naturaleza.

Por lo anterior, el argumento de la sustitución fue dicho como obiter dicta. En efecto, aunque la resolución exenta hubiese contenido la regla contraria, esto es, que ninguna institución privada con convenios vigentes con el Ministerio de Salud podría hacer objeción de conciencia, de todos modos, debería haber sido declarada antijurídica por invadir la potestad reglamentaria presidencial. Así, tal argumento no es determinante para arribar a la decisión final porque el continente jurídico de la decisión no era el idóneo. En consecuencia, pienso que tal argumento no es un precedente vinculante para la Administración.

Así, el presidente de la República podría haber regulado la forma de hacer la objeción de conciencia de las instituciones sin haber infringido su obligación de obedecer la jurisprudencia administrativa de la CGR. Con todo, nada impide que el argumento de la sustitución sea adoptado en una decisión ya no como precedente obligatorio, sino en su propio mérito. Pero en ese caso, la decisión no se puede fundar en simplemente "estar obedeciendo el precedente", sino que el órgano debe justificar porque está "considerando" en su decisión un contenido que no estaba desde un punto de vista jurídico obligado a seguir.

\section{b) ¿Aclarar o reconsiderar? La fundamentación del cambio de criterio}

Identificar la ratio decidendi de un pronunciamiento también sirve para determinar cuándo corresponde aclarar el contenido de un precedente o abandonarlo. Existen casos en que la CGR ha "aclarado" un precedente en el entendido que este seguirá vigente en circunstancias que un análisis de la regla de derecho aplicada y los hechos sobre los que recayó muestran que se tratan de pronunciamientos incompatibles entre sí. Lo anterior, como se señaló en el apartado anterior, también genera problemas con la fundamentación del acto administrativo, lo que, en este caso, ha llevado a que el acto sea impugnado ante los tribunales.

Para esto se puede considerar el caso "Corporación de Asistencia Judicial Metropolitana con Contraloría Regional Metropolitana". En el año 2018 una asociación de funcionarios consultó a la Contraloría Regional Metropolitana si podían contar como trabajada su hora de colación y, en consecuencia, si sus contratos debían ser ajustados y recibir un pago retroactivo por las horas correspondientes. El problema era si a estos funcionarios les era aplicable el artículo 34 del Código del Trabajo, que establece que la jornada de trabajo se interrumpe en el tiempo de colación, o las disposiciones del Decreto No 1897 de 1965 del Ministerio del Interior que establecía que la 
hora de colación debía computarse como tiempo trabajado en el caso de los servidores públicos.

En relación con este asunto, la CGR tradicionalmente sostuvo que el Decreto Supremo No 1897 obligaba a computar como trabajada la hora de colación en el caso de los funcionarios públicos regidos por el Código del Trabajo53. Sin embargo, en el Dictamen N 70.674 de 2013 se cambió de parecer y se declaró que la hora de colación no debía computarse como trabajada porque el Código del Trabajo era la norma específica que regulaba la materia. Así, no era aplicable el Decreto $N^{\circ} 1897$. No obstante, se volvió a cambiar de criterio en el Dictamen N 55.490 de 2016. En esa oportunidad, se resolvió que en el caso de aquellas jornadas de trabajo superiores a 43 horas semanales sí era aplicable el Decreto N 1897. Tal dictamen "aclaró" el contenido del Dictamen $N^{\circ} 70.674$ de 2013. Finalmente, sobre la base de este precedente (el Dictamen N 70.674 de 2013 aclarado por el Dictamen N 55.490 de 2016) la Contraloría Regional Metropolitana respondió la consulta de la asociación de funcionarios y resolvió que resolvió que la hora de colación debía computarse como trabajada por ser aplicable el citado decreto ${ }^{54}$. En contra de tal decisión la Corporación de Asistencia Judicial interpuso un recurso de protección.

La Corte Suprema decidió, en definitiva, acoger el recurso. Uno de sus argumentos fue que, ante la evidente antinomia entre el Código del Trabajo y el Decreto $N^{\circ}$ 1897, debía primar la norma de rango legal. Sin embargo, también es preciso tener en cuenta otro argumento de la Corte Suprema. La jurisprudencia administrativa tradicionalmente sostuvo que el Decreto No 1897 sí era aplicable a los funcionarios públicos regidos por el Código del Trabajo pues cumplían una función pública. Tal criterio fue "reconsiderado" en el Dictamen N 70.674 de 2013, donde se resolvió que los funcionarios se regían por el Código del Trabajo. Posteriormente, la CGR se pronunció "aclarando" el nuevo criterio para, en la práctica, volver al criterio anterior: que el Decreto $N^{\circ} 1897$ sí era aplicable. De este modo, la Corte Suprema le reprocha al recurrido el haber resuelto aplicar el Dictamen $N^{\circ} 55.490$, que "aclaró" al anterior, sin explicitar los fundamentos que lo hicieron volver al criterio reconsiderado por el Dictamen $N^{\circ} 70.674$ de $2013^{55}$.

Esto solo parece un complicado juego de precedentes y decisiones. Pero pienso que todo queda más claro si se hace el ejercicio de determinar la ratio decidendi de cada pronunciamiento. La regla de precedente establecida antes del dictamen de 2013 era la siguiente: los servidores públicos regidos por el Código del Trabajo pueden computar como trabajada su hora de colación por ser aplicable el Decreto N 1897, ya que cumplían una función pública. Tal regla fue reconsiderada por el Dictamen N 70.674 de 2013 cuya

\footnotetext{
53 Dictamen N 41.611 (1995); Dictamen N 10.550 (2009).

54 Dictamen Contraloría Regional Metropolitana No 11.832 (2018).

55 Corporación de Asistencia Judicial de la Región Metropolitana con Morales (2019), considerando $7^{\circ}$.
} 
ratio decidendi puede ser definida de la siguiente manera: a los servidores públicos regidos por el Código del Trabajo no les es aplicable el Decreto N 1897 porque se regían por el Código del Trabajo.

Pero es en este momento donde se produce una grave confusión. El Dictamen N 55.490 de 2016 entendió que el Decreto N 1897 sí era aplicable y, sobre la base del artículo $4^{\circ}$ del mencionado decreto, declaró que la hora de colación no se contaba como trabajada en el caso de aquellas personas que tuviesen una jornada inferior a 43 horas semanales, ya que la jornada "continuada" solo regía para quienes tuviesen más de esa cantidad de horas. De este modo, la CGR decidió "aclarar" el Dictamen N 70.674 señalando que en el caso de las jornadas inferiores a 43 horas no se computaba la colación como trabajada, pero en el caso de las jornadas de tiempo superior sí debía contabilizarse. Pero tal "aclaración" es una verdadera reconsideración. Esto se debe a que la ratio decidendi del Dictamen $N^{\circ} 55.490$ era la siguiente: el Decreto $N^{\circ} 1897$ sí es aplicable a los servidores regidos por el Código del Trabajo y, por tanto, pueden computar como trabajada su hora de colación en la medida en que su jornada supere las 43 horas.

Esta decisión mal puede "aclarar" a la anterior si son abiertamente incompatibles. En efecto, el Dictamen N $N^{\circ} 55.490$ de 2016 declara que el decreto citado sí es aplicable porque, aunque reglamentaria, es una norma específicamente dada para los empleados públicos. Mientras tanto, el Dictamen N 70.674 de 2013 señala que el decreto no es aplicable de ningún modo por existir una norma legal específica que resolvía el asunto. De este modo, aunque el criterio contenido en el Dictamen $N^{\circ} 70.674$ de 2013 en cierto sentido pervivía de modo accidental luego del Dictamen $N^{\circ} 55.490$ de 2016, se trata de dos pronunciamientos cuyos fundamentos son incompatibles entre sí.

Lo anterior no es irrelevante. De hecho, la Corte Suprema entendió que la CGR debía fundamentar su decisión de volver al criterio anterior al Dictamen $N^{\circ} 70.674$ de 2013. Esto porque la CGR no puede desentenderse de su deber de fundamentar un cambio de criterio simplemente declarando que está "aclarando" en dictamen anterior. Con todo, este problema se podría haber despejado con un análisis detallado de los hechos de cada pronunciamiento y la determinación de la ratio decidendi en cada caso.

\section{c) Hechos distintos, reglas distintas: la técnica de distinguir}

A pesar de existir un precedente, es posible sustraerse de la obligación de aplicar un determinado criterio en la medida que el aplicador de la norma pueda distinguir el caso concreto que se está decidiendo con aquel decidido en un pronunciamiento anterior ${ }^{56}$. Siguiendo el planteamiento que se ha hecho hasta ahora, aunque un precedente aparezca como formalmente aplicable, un órgano, con una decisión fundada en la existencia de elementos fác-

56 CROSS y HaRRIS 2004, 101. 
ticos que permiten distinguir el caso que tiene entre manos, puede apartarse de un precedente sin infringir el artículo 19 de la Ley $N^{\circ} 10.336$.

Para mostrar cómo puede ser aplicada la regla de distinguir, se puede considerar el caso "Asociación Nacional de Funcionarios del Servicio Nacional de Menores con Contraloría General de la República". En esa oportunidad, la CGR representó al Servicio Nacional de Menores (SENAME) las bases administrativas para la contratación del servicio de alimentación del Centro Metropolitano Norte del SENAME. En efecto, la Contraloría Regional Metropolitana denegó la posibilidad de contratar tal servicio ${ }^{57}$.

Dicha decisión se basó en una línea jurisprudencial que denegaba la posibilidad de que un servicio público contrate servicios de alimentación para sus funcionarios por no existir autorización legal expresa para ello y por no ser ello necesario para el cumplimiento de sus funciones ${ }^{58}$. Al respecto, la CGR ha precisado que el servicio de alimentación es necesario, por ejemplo, cuando se trata de pacientes de servicios hospitalarios, menores atendidos por el SENAME o por otros órganos como la Junta Nacional de Jardines Infantiles y la Junta Nacional de Auxilio Escolar y Becas, cuyas funciones consisten precisamente en la entrega de alimentación ${ }^{59}$.

A pesar de lo anterior, impugnada la decisión tomada respecto del SENAME, la Corte Suprema consideró que la situación era distinta. Apoyándose en los mismos dictámenes en que se denegó la posibilidad de contratar el servicio de alimentación en el pasado, señaló que en este caso particular el servicio de alimentación era necesario para el cumplimiento de los fines del servicio. En efecto, aunque el servicio de alimentación estaba destinado a los funcionarios del servicio, ello era necesario para el cumplimento de sus fines porque los funcionarios involucrados deben cumplir turnos de 12 horas y los protocolos de seguridad de Gendarmería de Chile que rigen en el recinto prohíben el ingreso de alimentos. En consecuencia, el recurso fue acogido y se ordenó tomar razón de las bases de licitación ${ }^{60}$.

Se puede destacar de este caso que existe un elemento que lo distingue de los anteriores resueltos por la CGR. Los turnos de 12 horas y la existencia de un protocolo de seguridad de Gendarmería hacen que podamos sostener que se trata de un caso distinto. Por esto, la Contraloría Regional Metropolitana, en lugar de haber aplicado el precedente que limitaba la posibilidad de dar un servicio de alimentación solo a los casos autorizados por ley y cuando por sus funciones el servicio deba prestar alimentación a sus funcionarios, podría haber remitido el caso a la Contraloría General porque

\footnotetext{
57 Oficio Contraloría Regional Metropolitana No 190 (2018).

58 Dictamen No 55.062 (2012); Dictamen No 751 (1985); Dictamen No 16.069 (2000); Dictamen $\mathrm{N}^{\circ} 12.767$ (1992).

59 Dictamen No 55.062 (2012).

60 González con Contraloría General de la República (2019), considerando 6.
} 
se trataba de una situación de hecho distinta, distinguible de los casos resueltos en los pronunciamientos anteriores.

De lo anterior fluye que, al cumplir con lo ordenado en el fallo, la CGR no necesita "reconsiderar" su criterio anterior. Solo necesita, fundadamente, distinguir este caso concreto de los decididos en forma anterior: aquellos en que el servicio de alimentación es necesario para que los funcionarios del servicio cumplan con sus funciones en forma adecuada. En este caso, teniendo en cuenta su propia terminología, la CGR podría haber "complementado" o "aclarado" el criterio anterior, en el entendido que la nueva jurisprudencia no es incompatible con lo que se resolvía en el pasado.

Sin embargo, en este punto se puede proponer una innovación. En lugar de "complementar" o "aclarar" un pronunciamiento, se podría utilizar el verbo "distinguir" para señalar aquellas situaciones en que, tratándose de casos con elementos que permiten separarlos de los anteriores, la CGR decide aplicar un nuevo criterio. Esto parece más adecuado porque en casos como el comentado no es que los pronunciamientos anteriores tengan una carencia que llenar (como dan a entender cuando se dice "complementa") o un punto oscuro o dudoso que es necesario aclarar. Solo se trata de casos distintos que es preciso resolver con criterios distintos. Por esto, el verbo "distinguir" describe mejor la operación que se está llevando a cabo.

Además de lo anterior, la falta de un análisis adecuado de los hechos que gatillaron el pronunciamiento de la CGR en un determinado sentido puede llevar a los operadores jurídicos a extender, en forma injustificada, un determinado criterio en casos distinguibles. Puede ocurrir que si los dictámenes de la CGR son mirados como textos legales unos y otros parezcan incompatibles. Pero ello podría resultar errado si se analizan los hechos que dieron lugar al pronunciamiento.

Esto se observa en la causa "Jorge Stambuk con Instituto de Desarrollo Agropecuario y otro". El recurrente, funcionario en un cargo de alta dirección pública (ADP) del INDAP, presentó su renuncia a causa de habérsela pedido su superior. Frente a ello, la institución decidió pagarle una indemnización por años de servicio equivalente a una sola remuneración mensual. Esto porque, aunque llevaba varios años sirviendo en ese servicio, solo completó un año en el cargo de ADP. Al respecto, una antigua jurisprudencia consideraba que para efectos de calcular la indemnización era necesario contabilizar todos los años servidos en una institución ${ }^{61}$. Pero tal criterio fue reconsiderado y se estableció que los funcionarios ADP debían haberse desempeñado más de un año ese cargo para tener derecho a la indemnización, con independencia de qué otros cargos hayan ocupado en el servicio en el pasado62. Con

${ }_{61}$ Dictamen N 37.474 (2008); Dictamen Nº 10.501 (2009); Dictamen No 56.817 (2009).

62 Dictamen $N^{\circ} 34.842$ (2010). 
esto, la Corte de Apelaciones de Santiago resolvió que el INDAP y la CGR habían actuado dentro de sus atribuciones y desestimó el recurso ${ }^{63}$.

A pesar de lo anterior, la decisión del INDAP y de los tribunales obedece a una mala interpretación de los precedentes de la CGR. Para demostrar esto, se analizará la jurisprudencia pertinente. Primero, hay que tener en cuenta el Dictamen No 37.474 de 2008. En este caso, un funcionario consultó a CGR por la indemnización por años de servicio que le correspondía luego de que le fuera pedida la renuncia en un cargo de ADP. En su caso particular había trabajado en varios períodos discontinuos en el Servicio Nacional de Capacitación y Empleo (SENCE) y terminó ocupando un cargo de ADP. La CGR resolvió que el artículo 154 del Estatuto Administrativo solo se refería a los años servidos en la respectiva institución, por lo que tenía derecho a una indemnización por seis años de servicio (el máximo), a pesar de que trabajó solo uno como funcionario de ADP.

Luego, en concordancia con este precedente, la CGR se pronunció por medio del Dictamen $N^{\circ} 10.501$ de 2009. En este caso, se resolvió que un funcionario que no tenía más de un año de servicio, aunque se le hubiese pedido en forma anticipada la renuncia, no tenía derecho a una indemnización por años de servicio, pues ese era el mínimo que exigía el artículo 154 del Estatuto Administrativo. Finalmente, la CGR respondió una consulta por medio del Dictamen N56.817 de 2009 donde señaló que para efectos de aplicar la indemnización por petición de renuncia del mencionado artículo 154 hay que computar todo el tiempo trabajado en la institución respectiva, en forma independiente de si se ocupó un cargo de ADP o no.

Esta era la jurisprudencia administrativa vigente hasta junio del año 2010. En esa fecha, se emitió el Dictamen No 34.842 de 2010 que, en teoría, cambió de criterio. El caso trató de un funcionario de la Caja de Previsión de la Defensa Nacional que fue nombrado en su cargo el 1 de agosto de 2009 por medio de sistema de ADP. Luego le fue pedida la renuncia con efecto desde el 1 de febrero de 2010. Como consecuencia de lo anterior, solicitó un dictamen consultando si tenía derecho a una indemnización por años de servicio. En favor de su petición, argumentó que se le pidió la renuncia antes de la expiración de su nombramiento, que, de haber llegado a término, habría completado más de un año de servicio.

Al respecto, la CGR resolvió que no le asistía tal derecho, pues su cargo era de exclusiva confianza y no cumplió el requisito exigido por ley para gozar del derecho a indemnización, esto es, "haberse desempeñado a lo menos un año en calidad de alto directivo público"64. Acto seguido, se declaró que los Dictámenes No 37.474 de 2008, N 10.501 de 2009 y N 56.817 de 2009 quedaban sin efecto en lo pertinente. Así, es evidente que la CGR entendió

\footnotetext{
${ }^{63}$ Jorge Stambuk con Instituto de Desarrollo Agropecuario y otro (2011), considerando $9^{\circ}$, confirmada por la Corte Suprema.

64 Dictamen $N^{\circ} 34.842$ (2010).
} 
que estaba cambiando de criterio respecto de esos pronunciamientos. Pero ello es una equivocación porque no se distinguió el caso de quien sirvió en otro empleo por más de un año antes de ser promovido a un cargo de ADP.

Como consecuencia de tal cambio de criterio, el INDAP, la CGR y los tribunales de justicia entendieron que los funcionarios en cargos de ADP tenían que haberse desempeñado por más de un año en sus cargos para tener derecho a indemnización por años de servicio, tal como se desprende del fallo de la Corte de Apelaciones de Santiago ya citado. Pero lo anterior es una interpretación errada del Dictamen N³4.842 de 2010 en relación con el Dictamen N 37.474 de 2008 causada por la falta de consideración de los hechos resueltos en cada dictamen.

Es claro que ambos pronunciamientos no se oponen en cuanto a la posibilidad de computar el tiempo servido en otros cargos en el pasado. En el caso resuelto por medio del Dictamen N³4.842 de 2010 era necesario desempeñarse más de uno año en un cargo de ADP para obtener la indemnización, pues el interesado había ingresado a la Administración en un cargo de ADP. Pero en el Dictamen N³7.474 de 2008 tiene un sustrato fáctico distinto: el interesado, habiendo trabajado en forma previa en el INDAP, le fue solicitada la renuncia antes de cumplir un año en el mismo INDAP, pero ahora en su cargo de ADP.

Siendo el sustrato fáctico distinto, pienso que la decisión de reconsiderar el Dictamen N 56.817 de 2009 y anteriores es un acto que carece de la debida fundamentación porque se trata de situaciones distintas que fueron asimiladas como si fuesen iguales. A pesar de lo anterior, el Dictamen $N^{\circ} 34.842$ de 2010 fue interpretado como un giro jurisprudencia que exigía a todos los funcionarios de ADP haberse desempeñado más de un año en sus cargos para tener derecho a indemnización en el caso que les fuese solicitada la renuncia, porque, en definitiva, el sustrato fáctico de los precedentes no fue considerado en la decisión ${ }^{65}$.

\section{Conclusiones}

En este trabajo se ha examinado la regla de stare decisis contemplada en la Ley $N^{\circ}$ 10.336. Respecto de la comprensión y aplicación que ha tenido hasta ahora se formularon críticas y se hicieron propuestas para mejorar su aplicación. A continuación, se enumerarán las principales conclusiones de este trabajo:

\footnotetext{
65 También se podría aplicar la técnica de distinguir en el Dictamen $N^{\circ} 17.971$ (2009), respecto de la jurisprudencia contenida en Dictamen $N^{\circ} 44.787$ (2002), Dictamen $N^{\circ} 53.164$ (2009), Dictamen No 58.910 (2006), Dictamen No 44.595 (2007), Dictamen No 55.815 (2007), Dictamen $N^{\circ} 5215$ (2006) y Dictamen N²6.396 (2007). Asimismo, la línea jurisprudencial iniciada en el Dictamen $N^{\circ} 17.971$ (2009) puede ser distinguida de aquella contenida en el Dictamen $N^{\circ} 610$ (2000). En otro caso, se han distinguido supuestos en forma acertada: ver Dictamen $N^{\circ} 24.231$ (2018) que complementó al Dictamen Nº 7961 (2018).
} 
1. La Ley $\mathrm{N}^{\circ} 10.336$ contiene una regla que eleva al rango de fuente formal del derecho la jurisprudencia de la CGR, esto es, el conjunto de precedentes emanados del organismo mencionado. En consecuencia, el precedente de la CGR tiene el carácter de norma jurídica obligatoria para casos distintos de aquel en que recayó un determinado pronunciamiento. Sin embargo, la jurisprudencia de la CGR opera como norma jurídica de un modo distinto que otras normas como las leyes o reglamentos: si bien ambos tienen un efecto general, se diferencian en que el precedente de la CGR no se refiere a un supuesto abstracto, sino a uno concreto, que se aplica a otros casos lo suficientemente semejantes.

2. El precedente de la CGR, para operar como norma jurídica con efectos generales, requiere de una adecuada publicidad. En los sistemas del Common Law la debida publicidad de los precedentes siempre se consideró como algo fundamental. Lo anterior puede ser explicado porque la publicidad es una exigencia elemental de seguridad jurídica para que toda norma pueda imperar. De este modo, los precedentes de la CGR, como toda norma jurídica de efectos generales, requieren ser publicados no solo como una buena práctica, sino que por un imperativo jurídico que encuentra su raíz en el principio de publicidad recogido en nuestro ordenamiento jurídico.

3. Los precedentes de la CGR no deben ser aplicados como textos legales generales y abstractos, sino como antecedentes referidos a casos particulares en la medida que el caso futuro resulte ser sustancialmente igual. De esta manera, los precedentes no deben ser aplicados como textos que contienen una descripción normativa subsumible en hechos futuros, sino como documentos que contienen un criterio de decisión que es aplicable a casos futuros lo suficientemente semejantes al ya resuelto. Por esto, se recogió la distinción entre ratio decidendi y obiter dicta que se utiliza en los países del Common Law, porque esta permite formular el contenido obligatorio de un precedente con referencia a su texto y a los hechos sobre los que recayó el pronunciamiento.

4. En ocasiones los informes emitidos en el pasado por la CGR son aplicados, por la misma CGR o por otras autoridades, en casos futuros sin la debida publicidad. Al respecto, se argumentó que esta es una exigencia de seguridad jurídica que toda norma de imperatividad general debe cumplir. Por esto, al menos, los pronunciamientos que se utilizan como precedentes deben estar publicados en la base jurisprudencial dispuesta por la misma CGR.

5. También los precedentes de la CGR en ocasiones son aplicados sin tener en cuenta los hechos o sustrato fáctico que dieron lugar a ellos. Al respecto, se argumentó que ello no es correcto pues los precedentes no son normas referidas a supuestos abstractos contenidos en una descripción normativa, sino decisiones que se aplican a casos análogos que presenten una similitud suficiente. De este modo, la no consideración del sustrato fáctico de un precedente (ya sea aplicándolo, aclarándolo o reconsiderándolo) puede 
desencadenar vicios en la fundamentación fáctica de una decisión de la CGR, ya sea porque se extiende un mismo criterio a situaciones, en esencia, distintas, o bien porque se resuelven con diverso criterio situaciones sustancialmente iguales.

\section{Bibliografía citada}

ÁvILA, Humberto (2016). Certainty in Law. Switzerland, Springer, 520 pp.

BERMÚDEZ, Jorge (2016). El principio de protección de la confianza legítima como fundamento y límites a la actuación de la Administración del Estado. En: Ferrada, Juan Carlos, Bermúdez, Jorge y URRUtiA, Osvaldo [eds.], Doctrina y enseñanza del Derecho Administrativo chileno: estudios en homenaje a Pedro Pierry Arrau. Valparaíso, Ediciones Universitarias de Valparaíso, pp. 223-239.

Boettiger, Camila (2009). El principio de la buena fe en la jurisprudencia de la Contraloría General de la República en materia urbanística. Revista de Actualidad Jurídica, vol. 19, No 1, pp. 309-326.

CORDERO, Luis (2010). La jurisprudencia administrativa en perspectiva: entre legislador positivo y juez activista. Comentario desde el dictamen sobre la píldora del día después. En: Universidad Diego Portales [ed.], Anuario de Derecho Público 2010. Santiago, Ediciones UDP, pp. 165-188.

CROsS, Rupert y HARRIS, J. W. (2004). Precedent in English Law. Oxford, Clarendon Press, $4^{\text {a }}$ edición, $246 \mathrm{pp}$.

De la CRUz, Alicia (2019). Contraloría General de la República: ¿Jurisdicción contenciosa administrativa?. Santiago de Chile, Der Ediciones, 317 pp.

Diez, Silvia (2008). El precedente administrativo: Fundamentos y eficacia vinculante. Madrid, Marcial Pons, $478 \mathrm{pp}$.

GuZMÁn Brito, Alejandro (2019): La interpretación administrativa en el derecho chileno. Santiago, LegalPublishing Chile, $2^{\text {a }}$ edición, 202 pp.

LeTelieR, Raúl (2014). Contra la confianza legítima como límite a la invalidación de actos administrativos. Revista Chilena de Derecho, vol. 41, N², pp. 609-634.

Madariaga, Mónica (1993). Seguridad jurídica y administración pública en el siglo XXI. Santiago, Editorial Jurídica de Chile, $2^{\circ}$ edición, 242 pp.

MILLAR, Javier (2012). El principio de protección de la confianza legítima en la jurisprudencia de la Contraloría General de la República: una revisión a la luz del Estado de Derecho. En: Contraloría General de la República, AA.V. La Contraloría General de la República: 85 años de vida institucional (1927-2012). Santiago, Contraloría General de la República, pp. 417-430.

OrRego, Cristóbal (2019). Derecho: conceptos fundamentales. Santiago de Chile, Círculo Legal Editores, $234 \mathrm{pp}$.

ORREGO, Cristóbal (2009). La objetividad del derecho como función de la subjetividad/objetividad del juez. Revista de Derecho de la Pontificia Universidad Católica de Valparaíso, XXXIII, pp. 599-619.

Roman, Cristián (2018). Dictámenes de la Contraloría General de la República y acción declarativa de mera certeza (comentario de la sentencia del Tribunal Constitucional rol N 3.283). En: Fermandois, Arturo y López, Francisco [eds.] Sentencias destacadas 2017. Una mirada desde la perspectiva de las políticas públicas (Santiago, Ediciones Libertad y Desarrollo), pp. 389-433.

Sото KLoss, Eduardo (1999). Acerca de la obligatoriedad de los precedentes en la actividad administrativa del Estado. Revista Chilena de Derecho, vol. XXVI, N², pp. 399-403.

Sото KLoss, Eduardo (1996). Derecho administrativo. Bases fundamentales. Santiago, Editorial Jurídica de Chile, T II, 486 pp.

Sото Kıoss, Eduardo (2012). Derecho administrativo. Temas fundamentales. Santiago, Legal Publishing Chile, $3^{\circ}$ edición, 966 pp.

VALDIVIA, José Miguel (2018). Manual de derecho administrativo. Valencia, Tirant lo Blanch, $448 \mathrm{pp}$. 
Vergara, Alejandro (2019). El derecho administrativo ante la jurisprudencia de la Corte Suprema: Líneas y vacilaciones. Revista de Derecho Administrativo Económico, № 28, pp. 5-175.

WiLlıams, Glanville (2013). Learning the Law. London, Sweet \& Maxwell, decimoquinta edición, 287 pp.

\section{Normas citadas}

Decreto Supremo No 67 del Ministerio de Salud, Aprueba Reglamento para Ejercer Objeción de Conciencia según lo dispuesto en el Artículo 119 tres del Código Sanitario. Diario Oficial, 23 octubre 2018.

Ley $N^{\circ} 21.030$, regula despenalización de la interrupción voluntaria del embarazo en tres causales. Diario Oficial, 23 septiembre 2017.

Ley $N^{\circ} 19.880$, establece bases de los procedimientos administrativos que rigen los actos de los órganos de la Administración del Estado. Diario Oficial, 29 mayo 2003.

DFL N 1 del Ministerio de Justicia, Código Civil de Chile. Diario Oficial, 30 mayo 2000.

Ley $N^{\circ} 19.039$, Establece normas aplicables a los privilegios industriales y protección de los derechos de propiedad industrial. Diario Oficial, 25 enero 1991.

Ley $N^{\circ} 18.410$ de 1985, crea la Superintendencia de Electricidad y Combustibles. Diario Oficial, 22 de mayo de 1985.

Decreto Ley No 3538 de 1980, crea la Comisión para el Mercado Financiero. Diario Oficial, 23 de diciembre de 1980.

Decreto Ley No 830 de 1974, Código Tributario. Diario Oficial, 31 de diciembre de 1974.

Ley N ${ }^{\circ} 10.336$, Ley sobre organización y atribuciones de la Contraloría General de la República. Diario Oficial, 12 mayo 1952.

\section{Jurisprudencia citada}

Dictamen N 751 (1985): Contraloría General de la República, 9 de enero de 1985.

Dictamen N 12.767 (1992): Contraloría General de la República, 27 de mayo de 1992.

Dictamen Nº 41.611 (1995): Contraloría General de la República, 27 de diciembre de 1995.

Dictamen No 16.069 (2000): Contraloría General de la República, 8 de mayo de 2000.

Dictamen N 610 (2000): Contraloría General de la República, 7 de enero de 2000.

Dictamen N 44.787 (2002): Contraloría General de la República, 4 de noviembre de 2002.

Dictamen N 58.910 (2006): Contraloría General de la República, 6 de diciembre de 2006.

Dictamen N 5215 (2006): Contraloría General de la República, 31 de enero de 2006.

Dictamen N 55.815 (2007): Contraloría General de la República, 7 de diciembre de 2007.

Dictamen N 50.185 (2007): Contraloría General de la República, 7 de noviembre de 2007.

Dictamen No 44.595 (2007): Contraloría General de la República, 4 de octubre de 2007.

Dictamen Nº 26.396 (2007): Contraloría General de la República, 12 de junio de 2007.

Dictamen No 14.292 (2007): Contraloría General de la República, 2 de abril de 2007.

Dictamen N 37.474 (2008): Contraloría General de la República, 8 de agosto de 2008.

Dictamen No 65.125 (2009): Contraloría General de la República, 20 de noviembre de 2009.

Dictamen N 56.817 (2009): Contraloría General de la República, 15 de octubre de 2009.

Dictamen No53.164 de 2009: Contraloría General de la República, 9 de noviembre de 2006.

Dictamen N 17.971 (2009): Contraloría General de la República, 8 de abril de 2009.

Dictamen No 10.550 (2009): Contraloría General de la República, 27 de febrero de 2009.

Dictamen N 10.501 (2009): Contraloría General de la República, 27 de febrero de 2009.

Dictamen N 34.842 (2010): Contraloría General de la República, 26 de junio de 2010.

Jorge Stambuk con Instituto de Desarrollo Agropecuario y otro (2011): Corte de Apelaciones de Santiago, 2 diciembre 2011.

Dictamen N 55.062 (2012): Contraloría General de la República, 5 de septiembre de 2012. 
Jorge Stambuk con Instituto de Desarrollo Agropecuario y otro (2012): Corte Suprema, 30 enero 2012.

Aserraderos Mininco S.A. con SAG (2013): Corte Suprema, 30 enero 2013.

Dictamen N 97.773 (2014): Contraloría General de la República, 17 de diciembre de 2014.

Dictamen Nº 40.086 (2015): Contraloría General de la República, 19 de mayo de 2015.

Abufrut Limitada con SAG y Fisco de Chile (2015): Corte Suprema, 28 mayo 2015.

Dictamen No 55.490 (2016): Contraloría General de la República, 27 de julio de 2016.

Sentencia TC Rol No 3729 (2017): Tribunal Constitucional, 28 agosto 2017.

Dictamen No 24.231 (2018): Contraloría General de la República, 28 de septiembre de 2018.

Dictamen No24.216 (2018): Contraloría General de la República, 27 de septiembre de 2018.

Dictamen No 11.832 (2018): Contraloría Regional Metropolitana, 17 de octubre de 2018.

Oficio No 190 (2018): Contraloría Regional Metropolitana, 5 de enero de 2018.

Dictamen No 11.781 (2018): Contraloría General de la República, 9 de mayo de 2018.

Dictamen No 7961 (2018): Contraloría General de la República, 22 de marzo de 2018.

Sentencia TC Rol No 5572 (2018): Tribunal Constitucional, 18 enero 2019.

González con Contraloría General de la República (2019): Corte Suprema, 24 julio 2019.

Corporación de Asistencia Judicial de la Región Metropolitana con Morales (2019): Corte Suprema, 22 julio 2019.

Dictamen N² 25.534 (2019): Contraloría General de la República, 25 de septiembre de 2019.

Dictamen No 16.587 (2019): Contraloría General de la República, 19 de junio de 2019. 